\title{
O Fluxo de Caixa como Ferramenta de Gerenciamento Financeiro de Pequenas Empresas
}

\section{The Cash Flow as Financial Management Tool For Small Businesses}

\author{
Recebido: 12/04/2015 - Aprovado: 22/05/2015 - Publicado: 27/06/2015 \\ Processo de Avaliação: Double Blind Review
}

\author{
Osmar Siena ${ }^{1}$ \\ Doutor em Engenharia de Produção (2002) \\ Mestre em Administração \\ Docente do mestrado e pesquisador da Universidade Federal de Rondônia. \\ osmar_siena@uol.com.br \\ Angelina Maria de Oliveira Licório \\ Mestre em Administração e em Direito \\ UNIR - Universidade Federal de Rondônia \\ clicorio@gmail.com \\ José Nilton Leite de Oliveira \\ Especialista em Controladoria e Gestão Financeira \\ Graduado em Ciências Contábeis e em Administração \\ Faculdade de Ciências Administrativas e de Tecnologia de Rondônia \\ jotanil@hotmail.com \\ Maria Laurimar de Matos Lima \\ Graduanda em Administração de Empresas \\ Faculdade de Ciências Administrativas e de Tecnologia de Rondônia \\ lauri_2008@hotmail.com
}

\begin{abstract}
Resumo: Este estudo está situado no eixo de Administração Financeira, com investigação sobre os fatores de controle de finanças empresariais em corporação de pequeno porte. Possui como objetivo geral analisar a ferramenta Fluxo de Caixa como instrumento para gerenciamento financeiro e como objetivos específicos descrever o processo de utilização da ferramenta de Fluxo de Caixa; analisar a viabilidade de implantação da ferramenta como instrumento de gerenciamento financeiro e sugerir propostas de adequação para implantação do Fluxo de Caixa como sistema de gerenciamento financeiro. Para atender a esses objetivos a pesquisa utiliza metodologia de natureza qualitativa e aplica os instrumentos de visita in loco, entrevista e aplicação de questionário para a coleta dos dados. É utilizada a análise descritiva que busca confrontar as bases teóricas e os dados obtidos com a investigação. Com a realização da análise foram alcançados os seguintes resultados: descrição dos processos da
\end{abstract}

\footnotetext{
${ }^{1}$ Autor para correspondência: Universidade Federal de Rondônia, Av. Presidente Dutra, 2965 , Centro, Porto Velho, RO, CEP: 76801-974.
} 
empresa pesquisada; identificação das necessidades e formas de controle utilizadas atualmente e apresentação de medidas de melhoria para o ajuste das inconformidades apontadas. O estudo contribui tanto para o aperfeiçoamento acadêmico pela análise de situação real da empresa, assim como serve de recomendação a empresas que enfrentam dificuldades similares quanto à gestão financeira.

Palavras-chave: Administração Financeira. Fluxo de Caixa. Gestão de Processos.

Abstract: This study is engaged on the axis of Financial Management, with research into the factors controlling corporation in small business finance. It has as main objective to analyze the cash flow tool as a tool for financial management and specific process to describe the use of the Cash Flow tool objectives; analyze the feasibility of implementing the Cash Flow tool as an instrument of financial management and suggest proposals for suitability for deployment of Cash Flows as a financial management system. Facing these objectives the research uses the precedence of qualitative methodology and applies the instruments on-site visit, interview and questionnaire to collect data. Descriptive analysis that confront the theoretical basis and the data obtained from research is used. With the completion of the analysis the following results were achieved: description of business processes researched; identifying the needs and forms of control currently used and presentation of improvement measures for the adjustment of non-conformities identified. The study contributes to both the academic improvement by analyzing the real situation of the company, as well as it serves as a recommendation to companies embracing similar difficulties in financial management.

Keywords: Financial Management. Cash Flow.Management. Processes.

\section{INTRODUÇÃO}

Em plena era da informação, não é novidade que as empresas produzam diariamente grande volume e variedade de dados. Também se torna cada vez mais difícil transformar esse conjunto de dados em informações gerenciais úteis para o processo de decisão.

Mesmo na era informacional, com a internet e outros sistemas automatizados em ascensão, precisa-se questionar o porquê da existência de dificuldades para o controle na gestão das empresas. Imagina-se que muitas empresas não tenham aderido às melhorias da era digital. Esse fato está mais relacionado aos modelos administrativos do que ao potencial que a empresa possui para realizar investimentos financeiros.

Defendendo a ideia de que microempresas sejam capazes de possuir estruturas processuais organizadas e controladas de forma sistêmica, propõe-se como objeto desta pesquisa analisar a utilização da ferramenta Fluxo de Caixa como proposta de inovação e aperfeiçoamento para o controle financeiro. 
Nesse contexto, pretende-se responder ao seguinte problema: a aplicabilidade do Fluxo de Caixa contribui para o gerenciamento financeiro? Para alcançar os resultados desta pergunta são levantados um objetivo geral e três objetivos específicos.

O objetivo geral consiste em analisar a ferramenta Fluxo de Caixa como instrumento para gerenciamento financeiro. E como objetivos específicos: descrever o processo de utilização da ferramenta de Fluxo de Caixa; analisar a viabilidade de implantação da ferramenta Fluxo de Caixa como instrumento de gerenciamento financeiro e sugerir propostas de adequação para implantação do Fluxo de Caixa como sistema de gerenciamento financeiro.

A relevância do estudo está centrada na apresentação da ferramenta Fluxo de Caixa como alternativa de melhoria aos processos administrativos e gerenciais. Busca-se identificar as necessidades e dificuldades encontradas pela organização quanto ao uso de sistemas para controles financeiros.

Para a investigação utilizam-se os modelos e instruções que serão apresentadas pelos autores no referencial desta pesquisa, buscando de tal forma demonstrar se o Fluxo de Caixa possui efetividade quando aplicado em pequenos negócios.

Para o atendimento das metas propostas são apresentadas as abordagens teóricas e conceituais que norteiam o tema da pesquisa. Estas servem para direcionar a análise e descrição dos resultados.

\section{REFERENCIAL TEÓRICO}

As premissas teóricas utilizadas objetivam embasar e direcionar o estudo, de modo que os conceitos defendidos pelos estudiosos e autores citados serão confrontados com o ambiente prático durante a investigação de campo. Será utilizada como teoria principal de suporte a Teoria de Sistemas, que Chiavenato (2003) descreve como conjunto de elementos interligados para constituir o todo. Para o autor, o sistema global apresenta o emergente sistêmico, que são as características e especificidades que não podem ser encontradas em elementos isolados.

O interesse em selecionar a Teoria de Sistemas em detrimento às demais se dá pela abordagem de Chiavenato (2003) que apresenta dois conceitos, a saber: (1) o de propósito, que é a finalidade do sistema e (2) o de globalismo, que identifica a natureza orgânica dos sistemas, onde a mudança em uma unidade afeta o sistema como um todo em um processo de ajustamento. 
Desse modo, ao analisar exclusivamente a funcionalidade da ferramenta de Fluxo de Caixa como instrumento de controle e, por conseguinte, sugerir medidas de ajustes ao processo, será possível identificar, por meio de um sistema de ajustamento contínuo, adequações para outras áreas organizacionais.

\subsection{FLUXO DE CAIXA COMO INSTRUMENTO DE GERENCIAMENTO FINANCEIRO}

As movimentações diárias realizadas pelas empresas necessitam de recursos financeiros. Essa administração de recursos para atividades financeiras diárias compõem a gestão de capital de giro ou capital circulante. Sobre esse termo, Braga (1995) define que a gestão de capital de giro envolve contínuo processo de tomada de decisões, as quais buscam preservar a liquidez da empresa, porém afetam diretamente sua rentabilidade.

Uma das principais dificuldades encontradas na gestão de capital é selecionar uma ferramenta eficiente que possa fornecer dados confiáveis para o processo decisório. Sobre essa dificuldade, Santos (2001) afirma que o Fluxo de Caixa é uma ferramenta de planejamento financeiro que objetiva fornecer estimativas da condição de caixa da empresa em determinado período para projeções futuras, contribuindo, portanto, para os sistemas de gestão e controle. Para Assaf Neto (2009) o Fluxo de Caixa torna-se ainda mais importante devido à facilidade de compreensão dos dados e auxílio para a tomada de decisão.

Para a gestão do Fluxo de Caixa devem ser observadas algumas variáveis específicas, que são resumidas no Quadro 1, as quais foram realizadas com base nas indicações de Assaf Neto e Silva (2002). 
Quadro 1 - Variáveis do Fluxo de Caixa

\section{VARIÁVEL}

1. Estrutura

\section{DESCRITIVA}

1.1 Depende da natureza da organização e de suas necessidades. O primeiro passo consiste em lançar os compromissos já assumidos, possuir estimativas e lançá-las no controle.

1.2 Algumas das contas são impostos, água, luz e até folha de pagamento; esses lançamentos e estimativas devem ser feitos no "contas a pagar". Posteriormente devem ser realizados os lançamentos em "contas a receber".

2. Estimativas 2.1 Servem para que os gestores tenham ideia de como agir nos períodos futuros; devem ser feitas estimativas de vendas à vista e vendas a prazo.

2.2 Os recebimentos podem ser sinalizados com o sinal de adição (+) e os investimentos e empréstimos contraídos podem ser sinalizados com o sinal de subtração (-).

2.3 Após todo o processo de controle do fluxo, o saldo final deve corresponder ao valor dos recursos disponíveis da empresa, tanto em banco de dados quanto em caixa físicos na organização.

Fonte: Adaptado de Assaf Neto e Silva (2002).

O SEBRAE - Serviço de Apoio às Micro e Pequenas Empresas (2014), afirma que durante o início do controle de Fluxo de Caixa algumas dificuldades vão surgindo, mas, com a prática efetiva do controle de caixa, gradualmente serão percebidas as vantagens dessa ferramenta para a tomada de decisão. Isso ocorre devido às informações que o gestor terá a respeito das previsões de entrada e saída de recursos.

\subsection{UTILIZAÇÃO DO FLUXO DE CAIXA}

O Fluxo de Caixa é um instrumento de gestão financeira que projeta para períodos futuros todas as entradas e as saídas de recursos financeiros da organização. Essas projeções servem de base para antecipar os saldos de caixa existentes para períodos vindouros. Para Gitman (1997), o Fluxo de Caixa é a espinha dorsal da empresa, pois sem ele não é possível saber quando haverá recursos para assegurar as operações e cumprimento das obrigações ou quando será necessário contrair financiamentos bancários. Sá (2008) define que é possível realizar o planejamento, análise e controle das finanças por meio do uso do Fluxo de Caixa. 
Hendrikse (apud Carneiro e Santos, 2009) afirma que a imprescindibilidade de se desenvolver demonstrativos de Fluxo de Caixa decorre do aumento de atividades operacionais complexas, ocasionando de tal forma desproporções entre o período no qual os lançamentos são apresentados e o período em que os fluxos de caixa ocorrem. Essa complexidade pode gerar ainda acentuada oscilação no Fluxo de Caixa.

Nesse contexto, as premissas apresentadas pelos autores enfatizam a necessidade do acompanhamento contínuo e rigoroso, o qual demanda práticas diárias para registro de receitas e despesas, bem como relacionam a significativa importância que o instrumento possui como ferramenta para a gestão financeira.

Outro fator relevante destacado para o uso desse mecanismo é apresentado por Goldratt e Cox (1990, p. 45) ao alertar que a calamitosa gestão do Fluxo de Caixa pode levar as empresas a declararem falência. Os autores citam que "é possível que vá à falência uma empresa que apresente lucro líquido e ainda um bom retorno sobre investimentos, isso ocorre pela má gestão do Fluxo de Caixa”.

Sá (2008) afirma que é fundamental a liquidez do Fluxo de Caixa, mesmo em situações de acentuada instabilidade econômica, causadas pela inflação ou recessão. Considera-se, portanto, que o Fluxo de Caixa não somente atua como controle de finanças, mas se torna um sistema de informação gerencial útil à identificação de possíveis problemas. Sobre os erros cometidos pelas empresas na configuração do Fluxo de Caixa, a especialista Priscila Zuini (2013), em reportagem à Revista Exame, apresenta quatro erros “imperdoáveis" cometidos pelos empresários no Fluxo de Caixa dos seus negócios. O Quadro 2, apresenta as descritivas relatadas pela jornalista, feitas com base nas recomendações de vários estudiosos da área de finanças corporativas. 
Quadro 2 - Principais inconformidades em um Fluxo de Caixa

\section{INCONFORMIDADE}

1. Ausência do plano de contas

2. Diferenciação entre previsão, receita e despesa

\section{Falta de acompanhamento}

\section{4. $\quad$ Adequar-se a} realidade

\section{DESCRITIVA}

1.1 Consiste em separar e categorizar os valores em subgrupos. Essa prática torna possível identificar o conjunto de gastos mais acentuados, melhores receitas e outras informações, possibilitando de tal forma a tomada de decisões estratégicas.

2.1 Equivale ao lançamento precipitado de receitas e despesas no controle financeiro. Há a necessidade do entendimento que: o parcelamento de receitas e despesas deve ser feito de acordo com o mês de referência no qual o débito/crédito será pago ou recebido, evitando a antecipação e o registro de um lançamento irreal em período específico.

3.1 Denota a questão da veracidade de informações registradas. O objetivo do Fluxo de Caixa é identificar previsões futuras, dessa forma o registro de dados passados prejudica o acompanhamento, bem como permite a existência de inconformidades ocasionadas pelo não lançamento de quaisquer registros financeiros.

4.1 Recomenda-se ainda o acompanhamento diário para que o gestor tenha conhecimento sobre a situação dos negócios, de forma que o possa avaliar mês a mês. Essa prática só é possível se os dados estiverem coordenados e expressarem a situação financeira real (e não a situação pretendida) da organização.

Fonte: Adaptado de Revista Exame.com - Pequenas e Médias Empresas PME. (2014)

Conforme apresentado no Quadro 2, as questões apontadas estão direta ou indiretamente relacionadas às formas de gestão da organização.

Tomando como base a fundamentação teórica, a adequação do modelo envolve mudanças nas funções administrativas e nos processos organizacionais. Frezatti (1997) aborda que a Gestão do Fluxo de Caixa é uma atividade interligada às demais funções empresariais. Destaca-se nesse contexto a criação de estruturas sistêmicas para observância de falhas e correção das inconformidades averiguadas no controle financeiro das empresas.

Desse modo, mais do que entender o conceito principal e a importância do uso do Fluxo de Caixa, torna-se necessário esclarecer como esse instrumento pode ser utilizado como um sistema para a gestão financeira. Assaf Neto e Silva (2002) citam que a prática do controle diário das receitas e despesas por meio do uso do Fluxo de Caixa vai se tornando mais fácil 
quando se associa às tarefas comuns da empresa. Nesse sentido, adequar o Fluxo de Caixa demanda conhecimentos específicos e atitudes de mudanças nas organizações.

\subsubsection{DEMONSTRAÇÃO DE FLUXO DE CAIXA}

Carneiro e Santos (2009) apresentam que a estrutura dos fluxos e demonstrativos deve contemplar aspectos específicos. Conforme apresentado no Quadro 3, o Fluxo de Caixa interage com outras formas de controle financeiro para compor a DFC - Demonstração de Fluxo de Caixa. Outro fator relevante sobre esse método trata da Composição do Fluxo de Caixa que Pinho (apud Carneiro e Santos, 2009) classifica em atividades operacionais, de investimento e de financiamento.

\section{Quadro 3 - Elementos da operação de Fluxo de Caixa}

\section{1 - COMPONENTES DO DEMONSTRATIVO}

\subsection{Caixa}

1.2 Equivalentes a Caixa
1.1 Integra o numerário em mãos e o depósito bancário disponível;

1.2 Investimentos em curto prazo e de alta liquidez, facilmente conversíveis em valores, os quais estão sujeitos a irrisórios riscos de mudança de valor.

\section{2-TIPOS DE FLUXO FINANCEIROS}

\subsection{Fluxo de Caixa $\quad 2.1$ Entradas e saídas de caixa equivalente ao caixa;}

2.2 Fluxo de 2.2 Principais atividades geradoras de receita da empresa e outras Operações atividades diferentes das de investimento e financeiras;

\subsection{Fluxo de 2.3 Aquisições e venda de ativos permanentes e demais Investimentos investimentos não inclusos nos equivalentes ao caixa;}

2.4 Fluxo de 2.4 Atividades que resultam em mudanças no tamanho e na Financiamentos composição do capital e empréstimos a pagar da empresa.

Fonte: Adaptado de Carneiro e Santos (2009).

Quanto às formas de apresentação da DFC, Marion (2003) indica dois modelos, o Método Direto e o Método Indireto. O Método Direto permite melhor apresentação e compreensão das transações de encaixe de desembolso do caixa. Marion (2003) define o 
Método Direto também como Fluxo de Caixa no sentido restrito. Neste modelo são apontados primeiro os elementos de entrada e saídas, apresenta-se o valor de receitas de vendas de bens e serviços e logo são subtraídos os diversos pagamentos, os quais incluem salários, encargos e fornecedores.

O Modelo Indireto integra, ainda, o lucro líquido da Demonstração de Resultado de Exercício - DRE - e os valores de depreciação, amortização, provisões para devedores duvidosos, aumento ou diminuição relativa a fornecedores e valores de contas a receber. No Quadro 4 é demonstrada a comparação entre os dois modelos.

Quadro 4 - Modelos de Apresentação de Fluxo de Caixa.

\begin{tabular}{|c|c|}
\hline Modelo Direto & Modelo Indireto \\
\hline Período de 19X2 & Período de 19X2 \\
\hline a) Atividades Operacionais & ATIVIDADES OPERACIONAIS \\
\hline Recebimentos de Vendas & Lucro Líquido apurado no /exercício \\
\hline (-) Pagamento de Compras & + Depreciação \\
\hline $\begin{array}{l}\text { Caixa Bruto obtido nas Operações } \\
\text { (-) Despesas Operacionais Pagas de Vendas Administrativas }\end{array}$ & Lucro que afeta o Caixa \\
\hline Caixa Gerado no Negócio & $\begin{array}{l}\text { Variações no Circulante (Capital de Giro) } \\
\text { Ativo - Aumento de Duplicatas a Receber (reduz o Caixa) }\end{array}$ \\
\hline b) Atividades de Investimentos & - Aumento de Estoques (reduz o Caixa) \\
\hline $\begin{array}{l}\text { (-) Aquisição de permanentes } \\
\text { Móveis e Utensílios }\end{array}$ & $\begin{array}{l}\text { Passivo - Aumento de Fornecedores (melhora o Caixa) } \\
\text { - Aumento de Impostos a Pagar (melhora o Caixa) }\end{array}$ \\
\hline $\begin{array}{l}\text { Terrenos } \\
\text { Ações de Outras Cias. }\end{array}$ & Caixa Gerado nos Negócios \\
\hline Caixa Gerado após as Operações de Investimento & $\begin{array}{l}\text { ATIVIDADES DE INVESTIMENTOS } \\
\text { Aquisição de permanentes }\end{array}$ \\
\hline c) Atividades de financiamentos & - Móveis e Utensílios \\
\hline Integralização de Capital & - Terrenos \\
\hline $\begin{array}{l}\text { Empréstimos Bancários } \\
\text { (-) Dividendos Pagos }\end{array}$ & - Ações de Outras Cias. \\
\hline Caixa Gerado após as Operações Financeiras & $\begin{array}{l}\text { ATIVIDADES DE FINANCIAMENTOS } \\
\text { - Integralização de Capital }\end{array}$ \\
\hline Resultado Final de Caixa & $\begin{array}{l}\text { - Novos Empréstimos Bancários } \\
\text { - Dividendos Pagos }\end{array}$ \\
\hline + Saldo Existente em 31-12-X1 & RESULTADO FINAL DO CAIXA \\
\hline Saldo Existente em 31-12-X2 & + Saldo Existente em 31-12-X1 \\
\hline & Saldo Existente em 31-12-X2 \\
\hline
\end{tabular}

Fonte: Adaptado de Marion (apud Carneiro e Santos, 2009).

O Fluxo de Caixa pode ser elaborado manualmente, mas, para a maior confiabilidade do processo é viável o uso de planilhas eletrônicas ou uso de programas específicos de gestão. Como citam Carneiro e Santos (2009) na comparação dos métodos é preciso entender que cada empresa é única e isso significa que o fluxo deve ser ajustado à realidade da empresa.

Santos (2001), afirma que o planejamento do Fluxo de Caixa não é algo fácil, uma vez que trata com números incertos com previsões, porém, o resultado pós-implementação 
justifica positivamente todo o esforço destinado à atividade. Frezatti (1997) também defende que planejar o Fluxo de Caixa proporciona vantagens para a empresa.

\section{METODOLOGIA}

Siena (2007) afirma que a metodologia pode ser entendida como a etapa onde são explicitadas as abordagens e os procedimentos que foram adotados na realização da investigação. Como abordagem, esta pesquisa adota a de natureza qualitativa, pois permite a flexibilidade para interpretação do problema de pesquisa. Segundo Flick (2004), na pesquisa qualitativa as teorias servem como base para questionamentos, estudos e formulação de novas teorias.

Os métodos e procedimentos de pesquisa são descritos por Severino (2007) como as técnicas para coleta de dados por meio de atividades operacionais práticas de realização pesquisa, os quais devem ser determinados e compatíveis com a metodologia utilizada no estudo. No Quadro 5 serão apresentadas as estruturas de coleta de dados empregadas nesta pesquisa.

Quadro 5 - Métodos e Procedimentos de pesquisa

\section{PROCEDIMENTO}

1. Pesquisa in loco

2. Entrevista

3. Questionário

\section{DESCRITIVA}

1.1 Observações realizadas no local de pesquisa, que permitiu obter dados de forma visual, bem como conhecer a estrutura física e os recursos materiais que a organização dispõe; esclareceu ainda os processos, comportamento e desempenho do corpo funcional da empresa.

2.1 A entrevista foi aplicada com o gestor da empresa, onde foi possível obter a descrição do funcionamento dos processos, bem como esclarecimento de pontos não atingidos pela aplicação do questionário direcionado.

31 O questionário foi construído por questões sistematizadas sobre o assunto de interesse da investigação. Envolveu questões abertas e fechadas, as quais permitiram conhecer aspectos direcionados da pesquisa.

4.1 A análise descritiva foi aplicada como último instrumento de coleta; essa ferramenta objetivou relatar características dos processos ou atividades realizadas. Reunindo as informações da pesquisa in loco, entrevista e questionário, a análise descritiva compilou os dados e 
permitiu o confronto entre causa e efeito da pesquisa.

Fonte: Adaptado de Severino (2007).

Utilizando tais procedimentos foi possível obter os dados da pesquisa que foram analisados, confrontados com o levantamento teórico e onde são apresentados os resultados finalizados.

\subsection{LOCAL DE PESQUISA}

A pesquisa foi aplicada em uma empresa familiar situada no município de Porto Velho, estado de Rondônia, Brasil. A estrutura da unidade consiste em uma organização de pequeno porte do segmento de prestação de serviços que atua há 15 anos no ramo de impressão gráfica.

Atualmente a empresa conta com uma equipe de seis colaboradores e apresenta gestão centralizada, realizada pelo proprietário do empreendimento. $\mathrm{O}$ faturamento da empresa nos últimos cinco meses (janeiro a maio de 2014) apresenta receita média de $\mathrm{R} \$ 70$ mil (setenta mil reais), onde o gerenciamento financeiro não é realizado pela utilização de sistema informatizado específico para a tarefa.

Com a investigação de campo e levantamento de dados foram obtidas informações, que mediante análise permitiram averiguar os processos da empresa.

\section{ANÁLISE E DEMONSTRAÇÃO DE RESULTADOS}

Com base na pesquisa de campo e a aplicação dos procedimentos de metodologia foram alcançados os resultados da investigação, que por meio de análise descritiva foram resumidos e confrontados com o levantado teórico e conceitual que nortearam este estudo.

\subsection{INSTRUMENTOS DE GERENCIAMENTO FINANCEIRO}

O modelo de gestão de finanças é caracterizado atualmente pelo registro e apontamento de informações de modo generalizado, onde se denota o controle de entradas e pagamentos diários. Na Figura 1 se ilustra o sistema utilizado para o registro de tais informações. De acordo com a Figura 1, os sistemas de controle são aplicados pelo uso de planilhas do aplicativo Microsoft Office Excel. Não foi identificada a utilização instrumentos de controles específicos ou registros mais detalhados sobre as operações diárias da empresa. 
Neste caso, configura-se o uso de ferramentas simplificadas para o controle financeiro da empresa.

Essa prática quando confrontada às recomendações de Assaf Neto (2009), que considera o Fluxo de Caixa como um mecanismo para o auxílio de decisões, torna-se um processo insuficiente, uma vez que exige somente a descrição sumária das operações de finanças.

Figura 1 - Planilha de acompanhamento financeiro

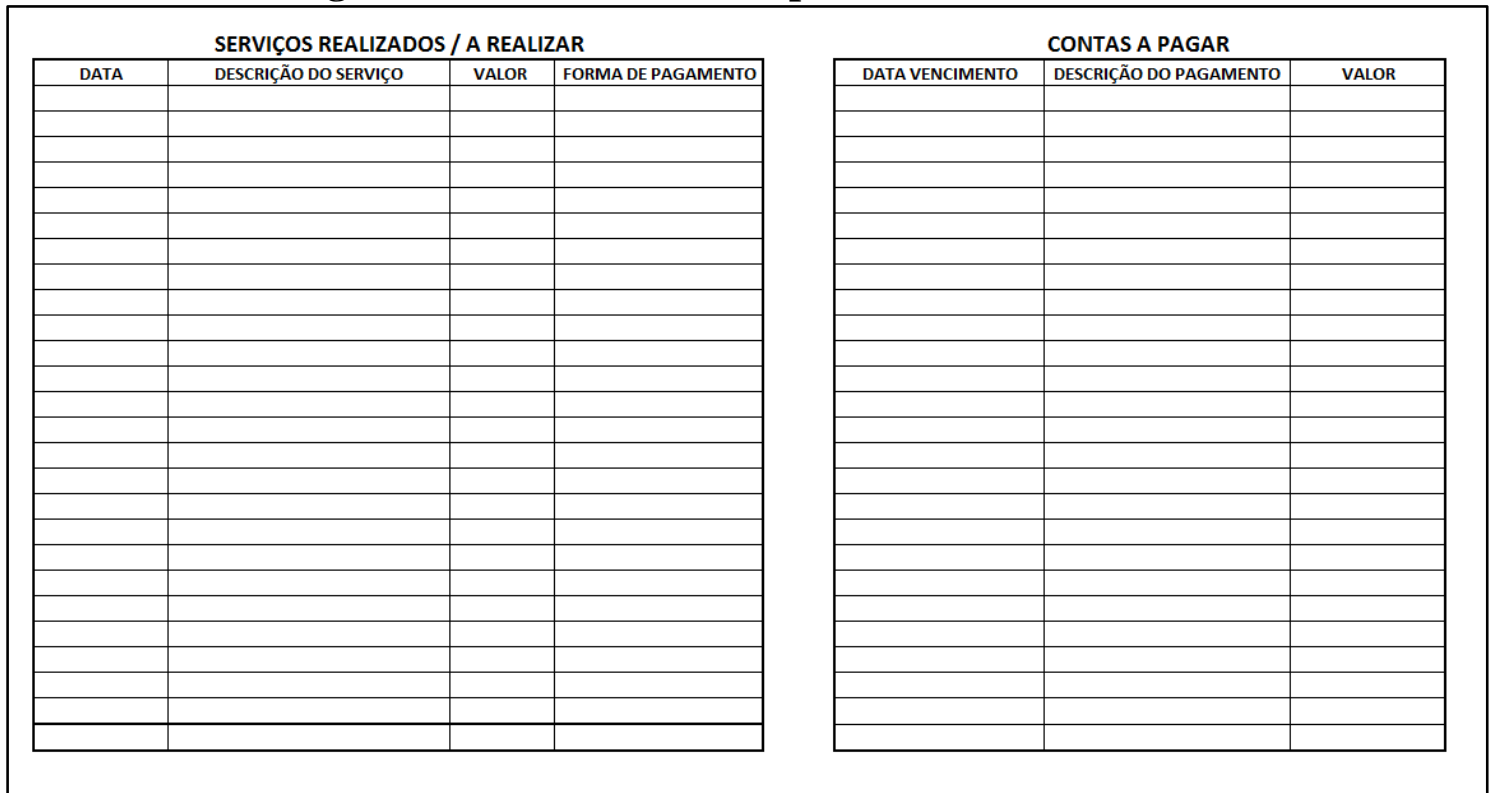

Fonte: Dados da pesquisa.

Segundo pesquisa, a empresa realiza reuniões mensais para tratar sobre o controle das finanças, de modo que ao fím de cada período são discutidos os processos da administração financeira. Embora se organizem tais reuniões com os colaboradores, inexiste o processo de prestação de contas para analisar os lucros e despesas do período.

Sobre esse fato, Frezatti (1997) e Sá (2008) afirmam que a ausência de acompanhamento das finanças e de seus resultados propicia inconformidades nos processos. Os autores conceituam que a gestão de finanças deve estar associada às demais atividades da empresa, onde é imprescindível registrar os dados financeiros, mas também é necessário discutir e analisar tais informações em vista de melhor eficiência na tomada de decisões. 


\subsection{GESTÃO DE FLUXO DE CAIXA}

Conforme levantado em pesquisa, a gestão é realizada por único responsável que supervisiona todas as tarefas da empresa e administra o controle das finanças. $\mathrm{O}$ administrador possui formação profissional em área divergente do segmento de atuação do empreendimento e afirma a necessidade de mudanças nos modelos de gestão financeira empregadas nos dias atuais.

Segundo o gestor, o controle financeiro é avaliado como regular, atendendo à demanda da organização, porém requisitando reformulação estratégica. Com o confronto entre dados da pesquisa e recomendações teóricas, é possível afirmar que as deficiências identificadas prejudicam não somente a veracidade do lucro líquido real, mas destaca o ineficaz controle de custos que pode acarretar em perdas e gastos desnecessários.

Em suma, é visível a demanda por modelos de inovação e novos conceitos de gestão financeira na unidade investigada. O modelo de Fluxo de Caixa utilizado não produz resultados eficazes, acentuando de tal forma a má gestão do capital financeiro.

Dentre os principais fatores apontados, o Quadro 6 demonstra o resumo da análise realizada na organização. 
Quadro 6 - Inconformidades dos Processos de Gestão Financeira

\section{INCONFORMIDADE}

1. Falta de Planejamento

Financeiro

2. Simplificação de informações lançamentos

3. Falta de acompanhamento diário

4. Desconhecimento da situação financeira real

\section{DESCRITIVA}

1.1 A empresa não realiza planejamento de despesas, investimentos ou compras futuras.

2.1 As informações de lançamentos financeiros possuem registro e superficial, ausente de detalhamentos e especificações. Tal fator prejudica a consulta e formação de um histórico financeiro confiável.

3.1 As operações e registros financeiros estão sujeitas a esquecimento ou erros de lançamento, uma vez que inexiste o confronto entre operações financeiras físicas e as informações lançadas.

4.1 A empresa não possui conhecimentos dos custos e receitas totais. O confronto entre despesas e receitas não é aplicado pela organização nem mesmo em periodicidade mensal.

Fonte: Dados da pesquisa.

Identifica-se como inadequações no processo de gestão a falta de Planejamento Financeiro e de acompanhamentos das operações e registros financeiros, o que resulta em um desconhecimento da real situação financeira da organização.

De acordo com as inconformidades apontadas, é sugerido um modelo de adequação ao processo, que é elaborado a partir das instruções teóricas levantadas no referencial teórico da pesquisa. 


\section{Quadro 7 - Medidas de adequação ao processo}

\section{ADEQUAÇÃO}

1. Assistente

Financeiro

2. Gestão diária dos lançamentos

3. Acompanhamento de despesas

4. Aperfeiçoamento do sistema de controle financeiro

\section{Planejamento financeiro e gestão}

\section{DESCRITIVA}

1.1 Selecionar um colaborador responsável exclusivamente pela gestão das finanças, o qual realizará os lançamentos, pagamentos e demais atividades financeiras.

2.1 O assistente deverá diariamente conferir se as operações financeiras estão em concordância com os valores lançados no sistema de controle informatizado.

2.2 O arquivamento de comprovantes e documentos deverá ser identificado e organizado em categorias específicas para facilitar a localização.

3.1 Deverão ser criados relatórios de receitas e despesas, de modo a obter dados sobre custos e previsões. Essa prática permite a visualização da situação real das finanças.

4.1 É necessário reformular o sistema atual de forma que proporcione melhor acompanhamento e registro de dados. Mesmo em planilha, a empresa deve estar atenta à segurança e especificação das finanças.

4.2 É sugerida a adoção de backups dos dados atualizados e a criação de novos modelos de planilhas (com cores de identificação, fórmulas e outras ferramentas como filtros e categorização dos dados);

4.3 Outro fator importante é o compartilhamento dos arquivos de finanças. Assim, sugere-se a criação de pasta pública para pessoas autorizadas. Isso permite a supervisão e facilidade de acesso aos documentos.

5.1 Recomenda-se rigor na criação do planejamento financeiro, uma vez que a empresa necessita de reformulação dos processos quanto à gestão de finanças. É sugerida a criação de metas para receitas e gastos, bem como o monitoramento do alcance de tais metas e o ajustamento das estratégias para execução das etapas planejadas.

Fonte: Dados da pesquisa.

No Quadro 7 são apresentadas as medidas de adequação sugeridas ao processo. Buscase a criação de estruturas mais eficazes ao processo atual, de forma que os recursos disponíveis sejam utilizados eficientemente. Assim, as melhorias e ajustes indicados são 
baseados na estrutura atual da empresa, ausente de investimentos financeiros. Com isso, é possível demonstrar que a gestão financeira pode atuar de forma saudável, mesmo em organizações de menor porte e que o Fluxo de Caixa, quando aplicado metodicamente, produz resultados significativos para o controle das finanças empresariais.

\section{CONSIDERAÇÕES FINAIS}

A realização do estudo permitiu demonstrar que o uso do Fluxo de Caixa contribui significativamente para o gerenciamento financeiro da empresa. Não somente como fator de organização das receitas e custos, mas como instrumento para a tomada de decisões e visualização da situação financeira real da organização.

Como identificado na pesquisa, a empresa estudada apresenta graves inconformidades nos sistemas de administração de finanças. Esse fato impossibilita definir se o empreendimento apresenta, atualmente, situação de lucro líquido positivo ou negativo, haja vista que inexiste o confronto entre receitas e despesas geradas pela empresa.

O estudo permitiu ainda inferir sobre uma situação real que representa a dificuldade de outras organizações quanto aos modelos de gestão e controle empregados para a administração dos recursos disponíveis. Pode-se afirmar nesse contexto, que a empresa propicia gastos excessivos e desnecessários, uma vez que também é ausente o planejamento de entradas e saídas financeiras. A falta de planejamento compromete ainda a expansão dos negócios, ampliação do segmento de atuação, lucratividade e outros fatores internos e externos que prejudicam a saúde financeira da empresa.

Ainda sobre esse estudo, a identificação de tais falhas fomentou o pensamento sistêmico, que por sua vez estruturou um modelo de ajuste das irregularidades identificadas nos processos analisados. Atendendo aos conceitos defendidos por Chiavenato (2003), a mudança em uma unidade do sistema proporciona a modificação nas demais partes do sistema global. Desse modo, a implantação das melhorias no setor financeiro irá refletir em melhores condições de trabalho em outras áreas da organização.

\section{REFERÊNCIAS}

ASSAF NETO, A.. Finanças Corporativas e valor. 4 Ed. São Paulo: Atlas, 2009. 
ASSAF NETO, A.; SILVA, C. A. T. Administração do Capital de Giro. $3^{a}$ Ed. São Paulo:Ed. Atlas, 2002.

BRAGA, R.. Fundamentos e técnicas de administração financeira. São Paulo: Atlas, 1995.

CARNEIRO, E. da; MENDES,J. D.; SANTOS, C. da C.. Fluxo de Caixa como ferramenta de Gestão Financeira. Artigo Científico. Universidade Católica de Goiás. Especialização em Gestão Financeira, Goiânia - GO, 2009.

CHIAVENATO, I.. Introdução à teoria geral da administração: uma visão abrangente da moderna administração das organizações. Rio de Janeiro: Elsevier, 2003.

CRESWELL, J. W.. Projeto de pesquisa: métodos qualitativo, quantitativo e misto. $2^{\mathrm{a}}$ ed. Porto Alegre: Artmed, 2007.

FLICK, U. Uma introdução à pesquisa qualitativa. 2a ed. Porto Alegre: Bookman, 2004.

FREZATTI, F. Gestão do fluxo de caixa diário: como dispor de um instrumento fundamental para o gerenciamento do negócio. São Paulo: Atlas, 1997.

GITMAN, L. J. Princípios de Administração Financeira. São Paulo: Harbra 1997.

GOLDRATT, E. M.; COX, J.. A meta: um processo de aprimoramento contínuo. São Paulo: Educador, 1990.

MARION, José Carlos. Contabilidade empresarial. 10ª ed. São Paulo: Atlas, 2003.

PME, Pequenas e Médias Empresas. Erros imperdoáveis no Fluxo de Caixa do seu negócio. Disponível em: <http://exame.abril.com.br/pme/noticias/4-erros-imperdoaveis-nofluxo-de-caixa-do-seu-negocio>. Acesso em: 02 mai. 2014.

SÁ, C. A.. Fluxo de caixa: a visão da Tesouraria e da Controladoria. $3^{a}$ ed. São Paulo: Atlas, 2008.

SANTOS, E. O.. Administração financeira da pequena e média empresa. São Paulo: Atlas, 2001.

SEBRAE - Serviço de Apoio às Micro e Pequenas Empresas. Fluxo de Caixa. Disponível em: <http://gestaoportal.sebrae.com.br/customizado/uasf/gestao-financeira>. Acesso em: 28 mar. 2014.

SEVERINO, A. J. (2007). Metodologia do trabalho científico. $23^{\mathrm{a}}$ ed. $5^{\mathrm{a}}$ reimp. São Paulo: Cortez, 2007.

SIENA, O.. Metodologia da pesquisa científica: elementos para elaboração e apresentação de trabalhos acadêmicos. Porto Velho: [s.n.], 2007. 
ZUINI, Priscila.4 erros imperdoáveis no fluxo de caixa do seu negócio. In Finanças | 08/11/2013. Exame.com. Disponível em <http://exame.abril.com.br/pme/noticias/4-errosimperdoaveis-no-fluxo-de-caixa-do-seu-negocio?page=2> . Acesso em: 28 mar. 2014. 